\title{
Metastatic carcinoid tumor with severe double valve disease at diagnosis: Case report and review of literature
}

\author{
Edna Juarez MD, Avinash Adiga MD, Paloma Sanchez MD, Hilal Fanasch MD
}

\begin{abstract}
A 27-year-old woman with a history of anxiety presented with three months of diarrhea. On physical examination, she had a grade 3/6 systolic heart murmur at the lower left sternal border which increased with inspiration, a grade 2/6 decrescendo diastolic murmur at the left sternal border, and lower extremity edema. Stool studies were negative. The abdominal ultrasound demonstrated multiple complex liver cysts. Transthoracic echocardiogram reported tricuspid valvular thickening with stenosis and regurgitation, severe pulmonary stenosis, and mild aortic regurgitation with valvular thickening. 5-hydroxyindole acetic acid and chromogranin A levels were elevated. The patient's symptoms improved after octreotide therapy, and she underwent tricuspid and pulmonary valve replacement.

The incidence of carcinoid tumors is 1.2 to 2.1 per 100,000 people in the general population. Carcinoid heart disease occurs in one-half to two-thirds of patients with carcinoid syndrome and is associated with poorer clinical outcomes. Left side cardiac involvement occurs in less than $10 \%$ of patients. The presence of both left and right sided valvular disease in the context of gastrointestinal carcinoid is associated with severe and poorly controlled disease. Up to $4 \%$ of these cases have metastatic disease on the valves, and $3.8 \%$ have direct myocardial involvement.
\end{abstract}

Keywords: carcinoid heart disease, carcinoid tumor, carcinoid syndrome

\section{INTRODUCTION}

Carcinoid syndrome occurs late in the clinical course of carcinoid tumors, often after five to eight years. The incidence of carcinoid tumors is relatively low in the general population (1.2 to 2.1 per 100,000 habitants per year) and usually is diagnosed in the fifth to seventh decade of life. One-half to two-thirds of those patients will develop carcinoid heart disease during their disease course. This case has an unusual early presentation of advanced carcinoid tumor at the time of diagnosis.

Corresponding author: Edna Juarez Contact Information: Edna.Juarez@ttuhsc.edu DOI: $10.12746 /$ swrccc.v5i21.416

\section{CASE}

A 27-year-old white woman with a past medical history of anxiety came to the emergency room (ER) complaining of right upper quadrant abdominal pain radiating to the shoulder and chest wall and "on/off" progressive fatigue for the past three months which had worsened over the last three weeks. She noted lower extremity and facial edema for which she had been seen multiple times in a local ER with no resolution of the symptoms. She also reported an episode of fever and diarrhea in the past two weeks, described as two to four loose stools per day, not bloody or foul-smelling, accompained by nausea and vomiting on two occasions and decreased oral intake due to reduced appetite. Her review of systems was positive for shortness of breath, diarrhea, and "panic attacks" 

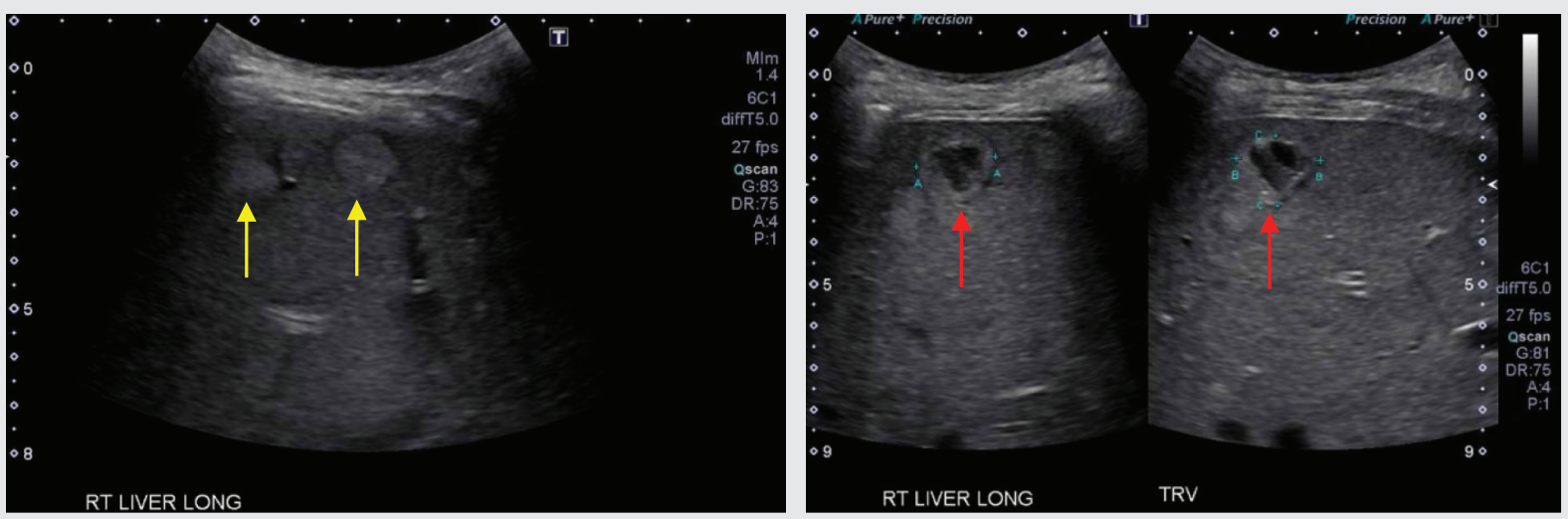

Figure 1. Liver ultrasound demonstrating multiple focal lesion throughout both lobes and all segments of the liver, some echogenic with target appearance (left) some are complex cyst (right) concerning for metastasis.

manifested by anxiety, palpitations, diaphoresis, and facial flushing.

On physical examination, patient had a hyperdynamic precordium, a grade $3 / 6$ systolic murmur along the left sternal border which increased with inspiration, a grade $2 / 6$ decrescendo diastolic murmur at the left sternal border, and bilateral lower extremity pitting edema to the distal tibia. The abdomen was soft with active bowel sounds and tenderness to palpation in the right upper quadrant. Lungs were clear to auscultation. No splinter hemorrhages, Janeway lesions, or Osler's nodes were noted.

Laboratory results on admission included D-Dimer $647 \mathrm{ng} / \mathrm{ml}$, BNP $364 \mathrm{pg} / \mathrm{ml}$, TSH $5.5 \mathrm{U} / \mathrm{ml}$, free T4 1.2 $\mathrm{ng} / \mathrm{dl}$, and free T3 $2.27 \mathrm{ng} / \mathrm{dl}$. Her urinalysis was normal. The complete blood counts included a WBC 15,000 with $66 \%$ neutrophils, $33 \%$ lymphocytes, and $10 \%$ monocytes. The C-reactive protein was $12.5 \mathrm{mg} / \mathrm{L}$, and a complete metabolic panel was unremarkable. Additional laboratory tests are reported in the Table.

An abdominal ultrasound identified multiple complex cysts (red arrow) in the liver, including some with a target appearance (yellow arrow), and a dilated common bile duct $(8.9 \mathrm{~mm})$ (Figure 1).

The transthoracic echocardiogram revealed mild aortic regurgitation, thickened tricuspid leaflets (within circle) with severe tricuspid regurgitation, moderate to severe pulmonic regurgitation, and a right ventricular systolic pressure of $61 \mathrm{mmHg}$. The inferior vena cava normal in size with less than $50 \%$ inspiratory collapse (Figure 2).

Urine collections for 5- hydroxyindole acetic acid (HIAA) and metanephrines were obtained. The patient continued to have diarrhea and started to have transient skin rashes. She was started on empiric therapy for carcinoid syndrome with octreotide TID, and her symptoms improved significantly.

Table. Diagnostic studies

\begin{tabular}{|l|l|l|}
\hline Laboratory test & Patient's value & $\begin{array}{l}\text { Reference } \\
\text { values }\end{array}$ \\
\hline $\begin{array}{l}24 \mathrm{~h} \text { urine } \\
\text { 5-HIAA }\end{array}$ & $366.9 \mathrm{mg} / 24 \mathrm{hrs}$ & $\begin{array}{l}6.0 \text { or less } \\
(\mathrm{mg} / 24 \mathrm{hrs})\end{array}$ \\
\hline Chromogranin A & $\begin{array}{l}300 \mathrm{ng} / \mathrm{ml} \text { (before } \\
\text { treatment) } \\
231 \mathrm{ng} / \mathrm{ml}(\mathrm{after} \\
\text { treatment })\end{array}$ & $\begin{array}{l}15 \mathrm{or} \text { less } \\
(\mathrm{ng} / \mathrm{ml})\end{array}$ \\
\hline $\begin{array}{l}\text { Echinococcus } \\
\text { antibody ELISA }\end{array}$ & Negative & Negative \\
\hline Isospora & Negative & Negative \\
\hline Cyclospora & Negative & Negative \\
\hline E histolytica Ag & Negative & Negative \\
\hline
\end{tabular}



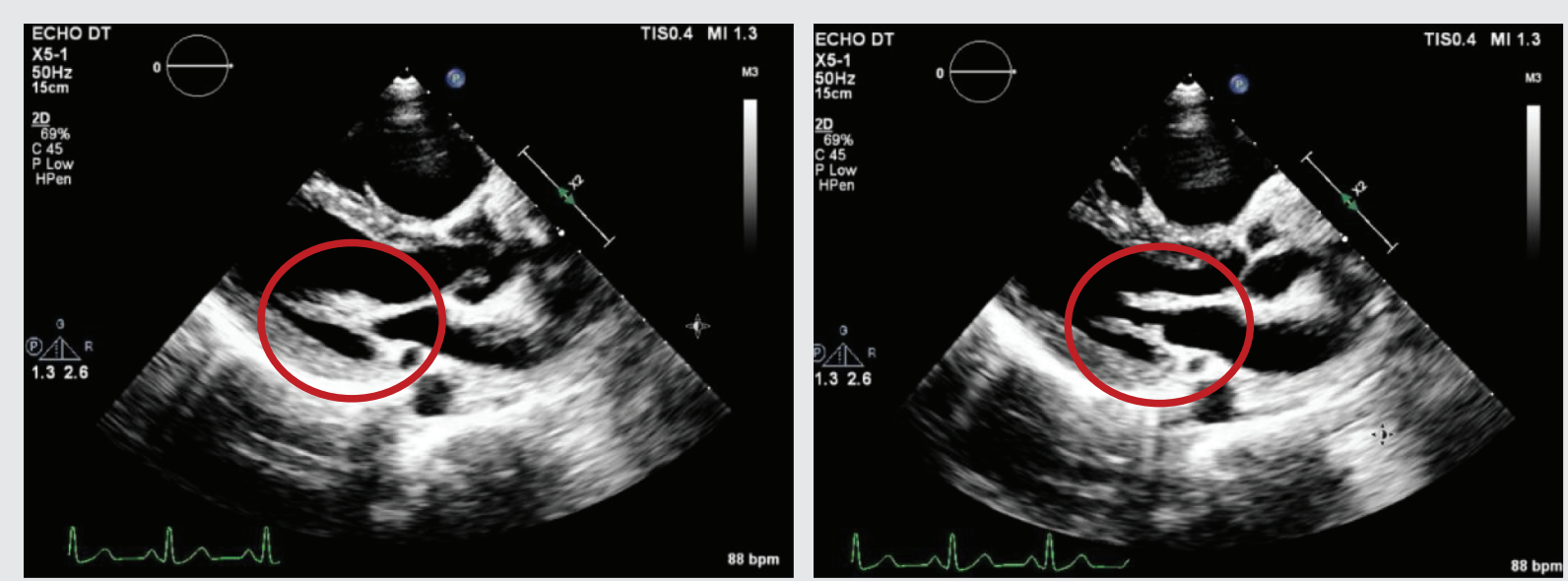

Figure 2. Transthoracic echocardiogram demonstrating thickened tricuspid leaflets with severe tricuspid regurgitation.

The patient underwent capsule endoscopy which showed a highly suspicious submucosal lesion at the illeocecal valve (Figure 3).
As a part of the work up the patient underwent an octreotide scan which revealed changes compatible with carcinoid tumor metastasis.

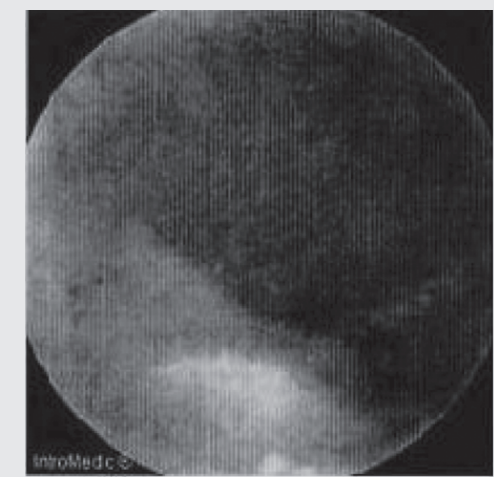

$02: 12: 55$

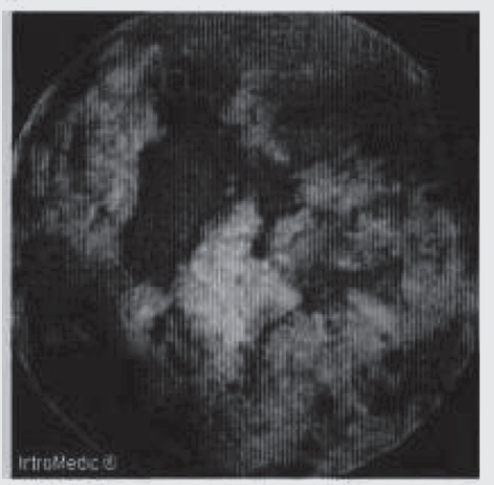

$09: 38: 49$

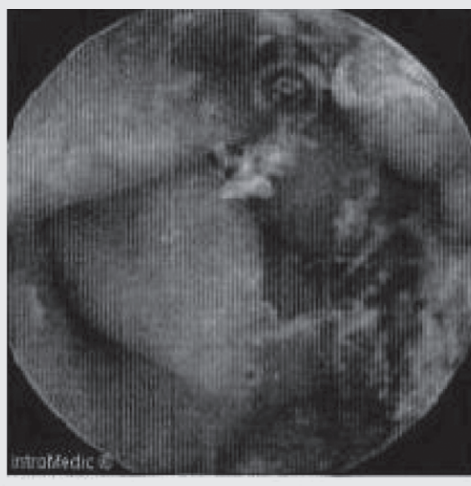

02:57:04

First lleo-cecal valve imaqe

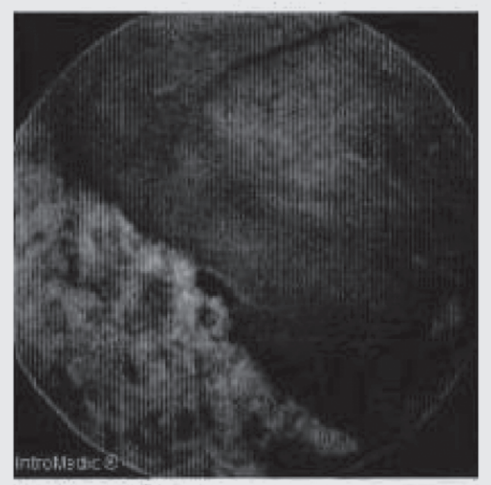

10:08:49

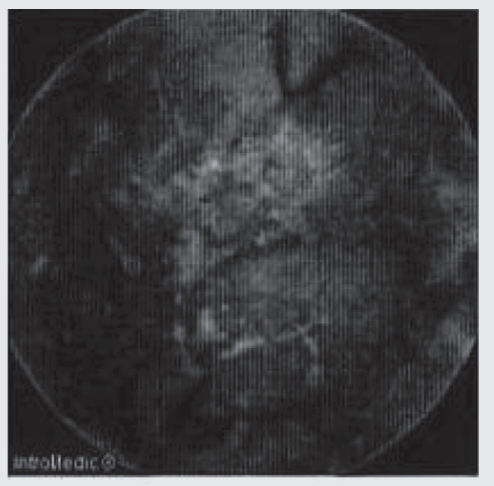

Figure 3. Capsule endoscopy demonstrating suspicious mass in the distal ileum and ileocecal valve.
$05: 58: 49$

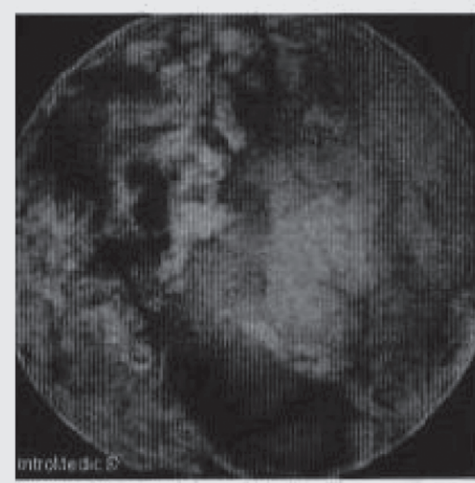

$10: 18: 49$ 

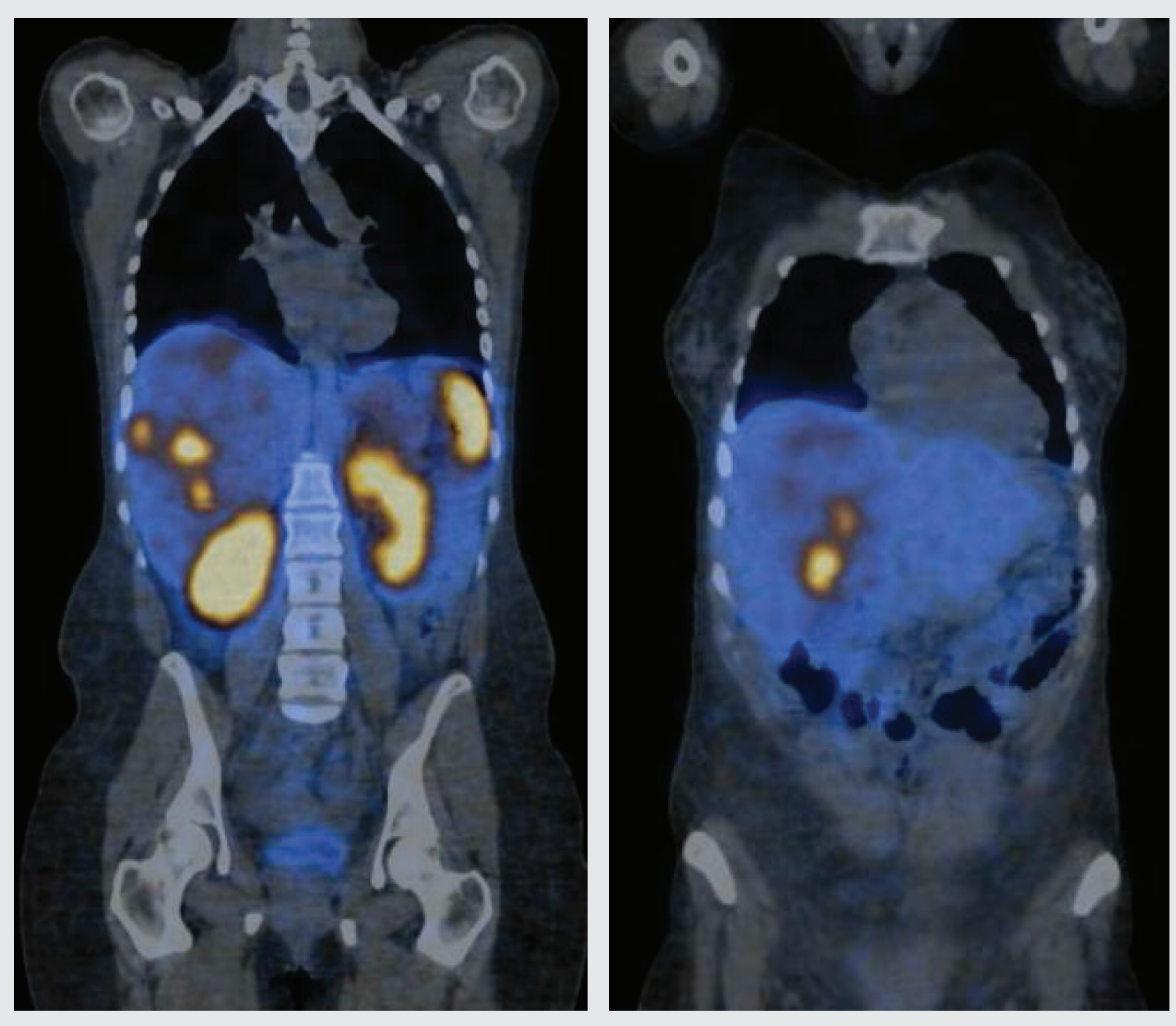

Figure 4. Octreotide scan reporting pathologic multifocal radiotracer activity in the liver compatible with carcinoid tumor metastatic disease.

Octreotide scan reporting pathologic multifocal radiotracer activity in the liver compatible with metastatic disease (Figure 4).

A liver biopsy revealed a neoplasm composed of cells with round nuclei and eosinophilic cytoplasm. The tumor cells are strongly positive for synaptophysin (center) and chromogranin (right); the tumor cells are arranged in trabecula (left) with minimal stromal fibrosis (Figure 5).

The patient was started on lanreotide $30 \mathrm{mg}$ IM monthly and followed as outpatient with monthly 5 -HIAA levels to adjust the dose of lanreotide.
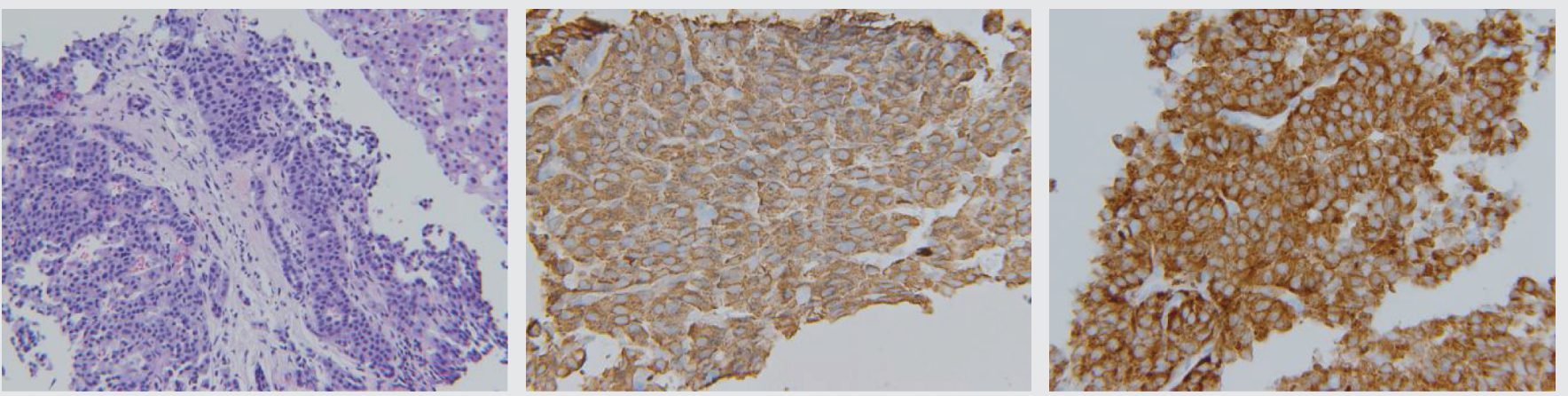

Figure 5. Liver mass needle biopsy immunostaining positive for chromogranin A and synaptophysin WHO grade 1 or 2. 
A repeat TTE revealed: a $D$ shape left ventricle with abnormal ventricular septal motion, a LVEF of $55 \%$, a mildly thickened tricuspid aortic valve, mild aortic valve regurgitation, a mildly thickened mitral valve, mild mitral regurgitation, a thickened pulmonary valve and pulmonary valve annulus, and moderate to severe right ventricular enlargement. There were increased systolic Doppler flow velocities across the pulmonary valve and the pulmonary valve systolic mean gradient was $12 \mathrm{mmHg}$. There was incomplete tricuspid valve cooptation, and the tricuspid valves were thick and immobile, resulting in severe tricuspid valve regurgitation. Tricuspid valve diastolic mean gradient was $4 \mathrm{mmHg}$. She underwent tricuspid and pulmonary valve replacement and was evaluated for the possibility of a liver transplant and surgical removal of the primary tumor.

\section{Discussion}

Neuroendocrine tumors (NETs) were first described by $\mathrm{Dr}$ Siegfried Oberndorfer in 1907. This particular subset of tumors includes a wide range of neoplasms which can arise from several different regions of the body, including the lung, pancreas, and gastrointestinal (GI) tract. They secrete active endocrine substances, such chromogranin-A and synaptophysin. Compared to other tumors, the incidence of NETs is increasing and ranges from 2 to 5 per 100,000 in the Western World, in contrast to the decreased incidence of most other malignancies. ${ }^{1}$ These rare neoplasms are more prevalent than gastric and pancreatic adenocarcinomas combined, are often undiagnosed because of the indolent nature of the disease, and affect primarily middle-aged patients. ${ }^{2,3,4}$ Neuroendocrine tumors have a spectrum of clinical courses from a median survival of two and five years with well or moderately well differentiated pancreatic and carcinoid tumors to only few months for high grade, aggressive neuroendocrine carcinomas. Symptoms range asymptomatic metastatic NETs to functional local tumors causing overt clinical syndromes. Neuroendocrine tumors are classified according to their primary tumor location, histological grade, and functional status. Neuroendocrine tumors can secrete monoamines, such as serotonin or peptide hormones, which lead to the carcinoid syndrome, a major cause of morbidity and mortality in these patients. ${ }^{5}$

During last decade, the American Joint Committee of Cancer (AJCC) and a Task Force of National Cancer Institute published recommendations and staging guidelines to stimulate the development of clinical trials to characterize the biology and clinical outcomes with these tumors. ${ }^{6}$ Under the general term "NET," several types of tumors are included. The World Health Organization has separated them into lung and GI NETs with the stage based on the histology, immunohistochemical markers for NETs (synaptophysin, chromogranin), tumor grade, mitotic rate, and $\mathrm{Ki}-67$ index. An alternative classification includes two large categories, the carcinoid and non-carcinoid tumors. The former is widely distributed in the GI tract, divided into foregut, midgut or hindgut carcinoids, or in the bronchus and lungs and rarely in the kidneys and ovaries. ${ }^{7}$

The incidence of carcinoid tumors is 1.2 to 2.1 per 100,000 people in the general population. ${ }^{8}$ Carcinoid syndrome represents a combination of signs and symptoms that adversely affect quality of life and potentially cause life-threatening complications. The symptoms of carcinoid syndrome typically occur between the fifth and seventh decades of life with a mean age of 55 to 60 years old, ${ }^{12}$ with a slight male preponderance $(60 \%)$. Only $20 \%$ of the cases present with cardiac involvement at the time of diagnosis. The diagnosis is often delayed at least two years from the onset of symptoms. ${ }^{13}$ Serotonin is the most important mediator in this syndrome. During the 1960s, the serotonin receptor antagonist methysergide was identified. ${ }^{9,10}$ The inhibitor of serotonin synthesis parachlorophenylalanine effectively reduced symptoms but also caused CNS toxicity. ${ }^{11}$ Somatostatin analog (SSA) treatment offers symptom relief in about $88 \%$ of patients. However, some patients may develop resistance due to tachyphylaxis or to increased tumor burden.

Carcinoid heart disease occurs in one-half to twothirds of patients with carcinoid syndrome and is associated with a worse clinical outcome; it is characterized by endocardial plaque like deposits. These lesions typically include myofibroblast proliferation and collagen deposition evident on Masson-trichrome stains and usually occur on right sided heart valves leading 
to a combination of valvular stenosis and regurgitation. Left sided cardiac involvement occurs in less than $10 \%$ of patients. However, when the primary carcinoid tumor arises in a pulmonary bronchus, this may result in the involvement of the left sided heart valves only. The presence of both left and right sided valvular disease in the context of gastrointestinal carcinoid is associated with both severe and poorly controlled disease. Up to $4 \%$ of these cases can have metastatic disease on the valves, and $3.8 \%$ have direct myocardial involvement. ${ }^{14}$ Surgical valve replacement in these patients has a 30 day mortality of $17 \%$ (range 1-63\%), but long-term survivors live an average of 58 months after surgery. Clinical studies demonstrate that surgical intervention improves the prognosis and reduces symptoms of heart failure. Post-operative mortality is mainly due to the carcinoid disease itself. ${ }^{15,16}$

\section{Conclusion}

Our case represents an unusual and early presentation of carcinoid syndrome in a 27-year-old woman who had severe pulmonary and tricuspid disease with right atrial enlargement at the time of diagnosis. She underwent successful valvular replacement. This case prompts us to have a higher index of suspicion for this diagnosis.

Article citation: Juarez E, Adiga A, Sanchez P, Fanasch $\mathrm{H}$. Metastatic carcinoid tumor with severe double valve disease at diagnosis: case report and review of literature. The Southwest Respiratory and Critical Care Chronicles 2017;21:26-31

From: Department of Internal Medicine, Texas Tech University Health Sciences Center, Lubbock, TX

Submitted: 5/12/2017

Accepted: 9/30/2017

Reviewer: Kenneth Nugent MD

Conflicts of interest: none

\section{REFERENCES}

1. Papaxoinis G, Syrigos K, Saif MW. New concepts in the treatment strategy of neuroendocrine tumors: The role of biotherapy. Discov Med 2016; 21(117): 381-9.
2. Kunz PL. Carcinoids and neuroendocrine tumors: Building on success. J Clin Oncol 2015; 1; 33(16):1855-63.

3. Yao JC, Hassan M, Phan A, Dagohoy C, Leary C, Mares JE, Abdalla EK, Fleming JB, Vauthey JN, Rashid A, Evans DB. One hundred years after "carcinoid": Epidemiology of and prognostic factors for neuroendocrine tumors in 35,825 cases in the United States. J Clin Oncol 2008; 26(18):3063-3072.

4. Mocellin S, Nitti D. Gastrointestinal carcinoid: Epidemiological and survival evidence from a large population-based study ( $n=25$ 531). Ann Oncol 2013; 24(12):3040-4.

5. Öberg K. Neuroendocrine gastro-enteropancreatic tumors from eminence based to evidence-based medicine - A Scandinavian view. Scand J Gastroenterol 2015; 50(6): 727-39.

6. Kulke MH, Siu LL, Tepper JE, Fisher G, Jaffe D, Haller DG, Benedetti JK, Bergsland EK, Hobday TJ, Van Cutsem E, Pinkpank J, Öberg K, Cohen SJ, Posner MC, Yao JC. Future directions in the treatment of neuroendocrine tumors: Consensus report of the National Cancer Institute Neuroendocrine Tumor clinical trials planning meeting. J Clin Oncol 2011; 29(7): 934-43.

7. Klöppel G, Perren A, Heitz PU. The gastroenteropancreatic neuroendocrine cell system and its tumors: The WHO classification. Ann N Y Acad Sci. 1014: 13-27, 2004.

8. Modlin IM, Sandor A. An analysis of 8305 cases of carcinoid tumors. Cancer 1997;79(4): 813-29.

9. Melmon KL, Sjoerdsma A, Oates JA, Laster L. Treatment of malabsorption and diarrhea of the carcinoid syndrome with methysergide. Gastroenterol 1965; 48: 18-24.

10. Melmon KL. Vasoactive substances in the pathogenesis of migraine headache, carcinoid syndrome and other diseases. Headache 1965; 5(3): 87-8.

11. Engelman K, Lovenberg W, Sjoerdsma A. Inhibition of serotonin synthesis by para-chlorophenylalanine in patients with carcinoid syndrome. N Engl J Med 1967; 277(21): 1103-8.

12. Anderson AS, Krauss D, Lang R. Cardiovascular complications of malignant carcinoid disease. Am Heart J 1977; 134(4):693-702.

13. Bernheim AM, Conolly HM, Hobday TJ, Pellikka PA. Carcinoid heart disease. Prog Cardiovasc Dis 2007; 49(6): 439-51.

14. Palaniswamy C, Frishman WH, Anorow WS. Carcinoid heart disease. Cardiol Rev 2012; 20(4): 167-76.

15. Manoly I, McAnelly SL, Sriskandarajah S, McLaughlin KE. Prognosis of patients with carcinoid disease after valvular surgery. Interact Cardiovasc Thorac Surg 2014; 19(2): 302-5.

16. Edwards NC, Yuan M, Nolan O, Pawade TA, Oleofse T, Singh H, Mehrzad H, Zia Z, Geh JI, Palmer DH, May CJ, Ayuk J, Shah T, Rooney SJ, Steeds RP. Effect of valvular surgery in carcinoid heart disease: An observational cohort study. J Clin Endocrinol Metab 2016; 101(1): 183-90. 